\title{
Metacognitive challenges to support self-reflection of students in online Software Engineering Education
}

\author{
Daniela Pedrosa* \\ Univ. Aveiro, CIDTFF, Aveiro, Portugal \\ $U T A D$, Vila Real, Portugal \\ 000-0001-9536-4234
}

Ceres Morais

INESC TEC, Porto, Portugal

UERN, Mossoró, Brasil

0000-0001-6270-2508

\author{
Teresa Bettencourt \\ Univ. Aveiro, CIDTFF, Aveiro, Portugal \\ 0000-0002-2913-952X
}

\author{
Tânia Araújo \\ Univ. Aveiro, Aveiro, Portugal \\ 0000-0002-6434-6735
}

\author{
Leonel Morgado \\ Univ. Aberta, Coimbra, Portugal \\ INESC TEC, Porto, Portugal \\ 0000-0001-5517-644X
}

\author{
José Cravino \\ Univ. Aveiro, CIDTFF, Aveiro, Portugal \\ $U T A D$, Vila Real, Portugal \\ 0000-0002-5376-6128
}

\begin{abstract}
Software engineering education requires students to develop technical knowledge and advanced cognitive and behavioral skills, particularly in the transition from novice to proficient. In distance learning, the hurdles are greater because students require greater autonomy, adopting strategies of self and co-regulation of learning. Facing these challenges, the SimProgramming approach has been transposed into the context of DL: e-SimProgramming. In the second iteration of e-SimProgramming implementation (2019/2020), one adaptation was inclusion of metacognitive challenges (MC) to promote students' self-reflection on their learning process. We explain the design of the two types of implemented MCs. We provide qualitative and quantitative analysis of: 1) evolution of MCs submission throughout the semester, identifying regularity and completion within deadlines and their relationship to student success; 2) students' perceptions of MCs. Results show a positive correlation between high MC submission and student success, greater interest and involvement of students in type 2 MCs and positive perceptions of students about MCs.
\end{abstract}

Keywords-metacognition, e-learning, software engineering education, self-regulated learning, SimProgramming

\section{INTRODUCTION}

Software engineering education is challenging, requiring novice students to master advanced technical skills and transition into experts by developing adequate cognitive and

* This work was financially supported by National Funds through FCT - Fundação para a Ciência e a Tecnologia, I.P., and CIDTFF (UIDB/00194/2020) - Universidade de Aveiro, Portugal, via Stimulus of Scientific Employment - CEECIND/00986/2017 Individual Support 2017, and via project PTDC/CED-EDG/30040/2017. We would also like to thank al students and teachers who collaborated on this research.

978-1-7281-6492-2/21/\$31.00 @2021 IEEE behavioral skills. It is a complex transition, requiring the combination of hands-on practice, educational plans, and adoption of metacognitive strategies.

These hurdles are compounded in online education, because distance learning (DL) students need to master greater autonomy over their learning process. Therefore, it is fundamental that they engage in self-regulated learning (SRL) strategies to succeed. However, students often struggle to self-regulate. Furthermore, DL students typically have more difficulties working together, due to personal circumstances (working students, with family responsibilities and living in different time-zones) leading to more difficulties in benefiting from the opportunities for co-regulation of learning.

To address these hurdles, we have been developing the eSimProgramming approach, an e-learning adaptation of the SimProgramming approach, originally developed for face-toface education [1]-[6]. The first version of e-SimProgramming was implemented in the academic year 2018/2019 [7], [8]. Several hurdles were identified, leading to changes in the academic year 2019/2020. Here focus on one of those changes: the adoption of metacognitive challenges to promote students' self-reflection. These implemented: 1) as fortnightly reflections (FR) about the students' learning progress (a change from previous FR), and 2) as questions to promote self-reflection about programming concepts.

\section{BACKGROUND}

In software engineering education, the novice-to-expert transition requires advanced technical skills [9], ability for abstract thinking, and adoption of metacognitive strategies 
[10]. The Software Engineering Competency Model (SWECOM) [11] highlights Cognitive Skills (reasoning, analytical skills, problem-solving, and innovation), Behavioral Attributes Skills (aptitude, initiative, enthusiasm, work ethic, willingness, and trustworthiness), and Requisite Knowledge Skills (cultural sensitivity, communication skills, team participation skills, and technical leadership skills). Major bodies in the field, ACM \& IEEE recommend connecting practical aspects of real practice with educational plans [9].

To successfully deal with the autonomy required in DL, students must be able to self-regulate their own learning, i.e. be actively involved in their learning: metacognitively, motivationally, and behaviorally [12]. The relationships between SRL and academic achievement are significant and positive across educational levels [13]. An important open question is how to support the development of SRL in online students.

SRL is a meta-process where students control and regulate metacognitive, cognitive, behavioural, emotional, and environmental aspects through the adoption of personal strategies to achieve established goals [14]. Metacognitive awareness is essential for students to control and monitor these aspects, obtaining success and good performance [15].

Metacognition is "thinking about thinking" [16], a continuous dynamic between monitoring and the capacity for self-judgment about the cognitive processes, and control the ability to use these judgments to change behaviour [17]. It is understood as an internal individual guide that enables awareness of processes and the adoption of strategies to learn (e.g. planning, analysis, management, monitoring) [18], [19]. Knowledge about one's own cognitive and motivational control involves emotional self-efficacy monitoring and assessment of metacognitive knowledge [20]-[22]. Metacognitive control are specific internal processes that guide regulatory behaviours of cognition allowing the development of SRL [17]. These allow students to develop their self-knowledge and teach themselves how to transfer and adapt to new learning environments [23]. This capacity for metacognitive regulation is a characteristic that distinguishes experts from novices [24].

However, there is a lack of instructional approaches encouraging students to become more metacognitive in relation to their learning [23]. Thus, it is recommended to design learning environments with instructional support for the development of metacognitive and SRL strategies [25]. Lin suggests two approaches to support metacognition [26]: 1) knowledge about a specific domain (e.g. programming content) and 2) knowledge about how to self-learn (e.g. self-knowledge). In DL, there is also a positive correlation between academic success and the adoption of metacognitive and SRL strategies [27], [28]. However, students have difficulties to adopt metacognitive strategies effectively [29]. It is essential to design pedagogical activities that allow the appropriate adoption of these metacognitive strategies and involve students in higher cognitive level activities [18], [28]. And in online instructional design the adoption of formative feedback is recommended, especially when students work in the same task over a long period, to help develop SRL during the execution of tasks and to provide opportunities for students to act according to this feedback [30]. Scaffolding is another strategy that helps students develop their knowledge construction [24]. Reflective (metacognitive) scaffolding is one of the types of strategies that can be adopted in DL, helping students understand their reflection processes by answering metacognitive questions [31].

The adoption of metacognitive strategies as reflection through self-tests with questions about the syllabus and on the monitoring of learning progress allows the promotion of student performance and involvement in DL [18]. These questions can be prompts, considered an effective instructional means to promote and guide the process of SRL, which can be conceived as requests for reflection before, during, and after the learning process [19]. Another strategy to prompt students' reflection in DL are reflection triggers [32]. These consist of structured opportunities that trigger mental regulation skills allowing students to analyse and evaluate their self-learning using study materials during learning activities [32].

One way to involve students in performing complex tasks, similar to real world contexts, is through challenges. Challenges are understood as an invitation or call to action structured in four parts that form a puzzle: the problem (e.g. tasks, questions, issues), the process (method and procedures for solving the problem), the product (the solution or the result obtained), and the criteria (guidelines for assessing the success obtained) [33]. We propose a new approach that articulates the different dimensions that involves a reflective metacognitive process with the concept of challenges: metacognitive challenges. Thus, metacognitive challenges arise as a process that involves the four dimensions of a puzzle associated with the components of the metacognitive process: problem (questions to promote the self-reflection); process (the triggers to provoke the self-awareness about the processes and methods that the student has to adopt during the learning process); product (the answer/solution for the next stages of task development), and the criteria (the evaluation options using a Likert scale).

\section{TEACHING CONTEXT AND LEARNING ASSIGNMENT}

The online asynchronous course "Software Development Laboratory " (LDS, Portuguese-language acronym), took place in the academic year 2019/2020, in 2nd semester of the 2nd year of the Informatics Engineering undergraduate programme at Universidade Aberta (UAb), using the Moodle platform, over 12 academic weeks. It is organized along a six-topic syllabus ( 2 weeks per topic) on software architectures, software engineering techniques, and coding approaches, scaffolding undergraduates transitioning from novice programmers into proficient programmers.

The learning goals are: 1) contact with environments, tools and software development methods, which allow the transition from individual projects to team projects, on a larger scale; 2) reflect and discover the best ways to develop software, minimizing costs and maximizing the quality of the software; 3 ) increase motivation and pleasure in developing software. 
The student cohort is heterogeneous in terms of age (24-60), gender (but predominantly male, 87,3\%), residency (throughout Portugal and abroad), and academic qualifications (including non-graduates and non-computing graduates). Typically students are already part of the workforce.

The course complies with an institutional rule that allows students to choose between two assessment paths during the first three weeks of the semester: 1) continuous assessment (assignments, called e-folios, and a written test, called p-folio), or 2) final assessment by written exam. In path 1, students were able to choose between two alternatives: 1.1 (team project) or 1.2 (individual project). All students were given the option to participate or not in this research, and the informed agreement included explicit consent for treatment and analysis of the data on their activity.

The teaching and learning methodology is based on the development of software projects by students or teams, following a prescribed project development sequence throughout the semester, with continuous assessment and three moments for converting that assessment as numerical grades, called e-folios. E-folios represent $40 \%$ of the LDS final grade, and a final written test comprises the remaining $60 \%$ (these percentages are mandated by institutional rules). The projectbased learning activities of topic 1 and 2 impact e-folio 1 , those of topic 3 and 4 impact e-folio 2, and topics 5 and 6 impact e-folio 3 .

There is no specific timetable for carrying out the activities. Students do them at their own pace, within the deadlines set for each topic. Activities include asynchronous forum discussions with lecturer and colleagues; performing metacognitive challenges; and formative assessment tests. In the final topic, students submit a final project report. Temporal flexibility is required by the UAb's pedagogical model [34]. During the two-week period for each topic, teaching monitors and encourages learning progress and interaction.

\section{DIFFERENCES BETWEEN THE FIRST ITERATION AND SECOND ITERATION OF E-PROGRAMMING APPROACH}

\section{A. The e-SimProgramming approach}

e-SimProgramming is an e-learning adaptation of the faceto-face SimProgramming approach [2]-[6], based on four conceptual foundations: (1) situated learning, (2) SRL; (3) CRL; and (4) formative assessment. Face-to-face teaching techniques were based on technological support [35], advocating problembased learning activities in a team, over four phases [3], with specific tasks of varying duration.

The first attempt to implement the SimProgramming approach in an e-learning context took place in the academic year 2015-2016, as part of a master's thesis [36]. This provided insights into the challenges and potential of adapting it to DL: the need for instruments supporting regulation of students' motivation and effort; team communication; strategies for providing feedback and time; and assessment strategies. This first exploration was the inspiration for the first version of e-SimProgramming [7], [8] in academic year 2018/2019.

\section{B. First iteration vs Second iteration of e-SimProgramming}

In the first iteration (academic year 2018/2019) [7], [8], the changes stemmed from adapting to the e-learning context of Universidade Aberta (asynchronous DL) and its pedagogical model [34], as described in section III. Further changes were introduced: the methodology became project-based instead of problem-based learning, leading to different tasks. The option to choose between two continuous assessment paths (group or individual) was also introduced. In that first research iteration, some hurdles were encountered [8]: 1) academic procrastination (e.g., students submitting only in the final topic); 2) students' difficulties adopting adequate SCRL strategies; 3) students' awareness problems of their difficulties.

Thus, in the second iteration (academic year 2019/2020) adaptations sought to address the hurdles of the first iteration: adoption of metacognitive challenges to promote students' self-reflection: 1) as fortnightly reflections (FR) about their learning progress (change from previous FR), and 2) as questions to promote self-reflection about programming concepts.

In this work, we focus on the change in FR, i.e. the moments of self-monitoring of the learning process by the students [2] [4], [8], [37] via metacognitive challenges.

\section{Fortnightly reflections vs Metacognitive challenges}

1) The Fortnightly Reflections (FR) approach: We used the Cravino et al. approach [37], adaptating the earlier FR approach used in the face-to-face context [2], [4]. Using a Google Forms questionnaire at the end of each of the 6 syllabus topics, students were asked to look upon their learning process and reflect, by answering the questions: 1) What tasks did I do in these two weeks? Was I able to carry out the requested tasks?; 2) Were there reasons preventing task completion? If so, which?; 3) What do I intend to do in the coming weeks?

With this, the pedagogical team monitored students' learning progress and adjusted pedagogical practices accordingly, e.g. identifying students' need of feedback or motivational support.

In the second iteration (academic year 2019/2020), the FR approach was replaced with two types of metacognitive challenges (MC): 1) MC as fortnightly reflections about the learning progress, and 2) $\mathrm{MC}$ to promote self-reflection about programming concepts. MC (both types) are triggered primarily by a character-led narrative (Catmming - a fictitious artificial intelligence [38]) that leads students to reflect through prompts (questions).

2) MC Type 1: Metacognitive challenges as fortnightly reflections about the learning progress: These MC (numbers 6, $10,13,15,17,18)$ are conceptually based on the previous FR approach [2]-[4], [37]. Questions in these MC were adjusted to the expected development status of the software throughout the course topics (initial, medium, or advanced), integrating aspects from students' metacognitive domain: self-confidence, self-assessment, and self-awareness. 
This type of MCs prompted students to reflect and selfassess their learning progress (awareness), the development status of their software, and their self-confidence about their work (self-efficacy). This is a sample narrative from these $\mathrm{MC}$, presented by the Catmming character, in MC 6 "My first 15 days at the SimProgramming Company!", which students encounter in topic 1:

\section{"Catmming: \\ Knock-Knock \\ After these first 15 days in contact with the Sim- Programming company and its work dynamics, how do you describe your experience so far?! Come on, reflect upon your progression!"}

After reading this narrative, the MC (implemented as a Moodle quiz) questioned students about their learning progress: 1) At what learning progression level do I believe to be within SimProgramming? Why?; 2) Did I experience difficulties integrating the SimProgramming company? If so, please describe the difficulties experienced in these past 15 days. How did you deal with them? If you did not, please explain why; 3) Did I manage to carry out all the tasks requested by the Boss? If so, indicate what strategies you adopted to carry out the activities. If not, explain the reasons for not having been able to carry out the activities.; 4) What are the next steps I will take in the next two weeks at SimProgramming?

In the subsequent MC, taking place fortnightly (MC 10, 13, $15,17,18$ ), other issues were included (similarly adjusted to the expected development status of the software project):

1) On students' self-confidence about their proposal, e.g. in MC10 - Do you have personal conviction/confidence that the proposal you're developing is clear and explicit, and abides by company procedures? Is it adequate to undergo the next development stages? Let's reflect...

2) On students' self-assessment about their learning progress and their software proposal under development. e.g. in MC13 - What is your self-assessment regarding the demonstration application prototype, regarding its suitability to undergo subsequent development stages? Explain the self-assessment you did.

3) On students' self-awareness about their difficulties and the strategies they adopted to overcome them; e.g. in MC15 - Did you experience difficulties in this software development stage? Why?

3) MC Type 2: Metacognitive challenges to promote selfreflection about programming concepts: These MC (MC numbers $1,2,3,4,5,7,8,9,11,12,14,16)$ prompt students to reflect upon their ability to apply the knowledge about technical aspects of software development processes, learned throughout the course.

The following narrative exemplifies these $\mathrm{MC}$, presented by the Catmming character. It is from MC 9 in topic 2, and based on two levels of Bloom's dimensions: metacognitive knowledge, and the cognitive process of analysis. The goals of this MC are: a) Students deconstruction of self-preconceptions regarding structuring of control and data flows; b) Students self-assessment on having enough knowledge to be able to structure control and data flows, in the context of their proposed software prototype.

"Catmming: Knock-Knock
Hi!
Do you feel it worthwhile to reflect upon the internal
structure of the application, dividing it into compo-
nents with different concerns? Or does it seem to you
that this wasted effort, without real effectiveness?
What aspects were most critical in making structural
decisions? Can you foresee a future situation where
changes to requirements or reacting to new problems
that may arise would be eased by this structuring?
Let's think about it ..."

After reading this narrative, which initiated a Moodle quiz, the MC questioned students about their self-awareness on the importance of structuring and decomposing the software development process as software architecture components, and led them to self-assess whether their knowledge and skills enabled this structuring and decomposition. In this example, one of the questions was: "What is my level of ability to foresee a future situation in which changes to requirements or problems to sort out are eased by this structuring?"

To answer, students would select on a Likert scale: Very Low; Low; Median; High; or Very High. Then students were asked to justify their choice.

\section{Methodology And data COllection}

Of the 50 students enrolled in the 2019/2020 academic year, 32 agreed to participate in the research. We adopted an exploratory qualitative and qualitative methodology [39] with the following goals: 1) understand what pedagogical phenomena occurred in the metacognitive challenges, during this second iteration; 2) describe and understand the relationships that exist between the metacognitive challenges, in particular the fortnightly reflections, and the level of learning progress achieved by the student throughout the various moments of continuous assessment (e-folios and p-folio) in LDS; and 3) identify which pedagogical improvements are needed in metacognitive challenges in the next iteration of e-SimProgramming.

We used quantitative descriptive analysis of the interactions with $\mathrm{MC}$ in the Moodle platform: number of submited metacognitive challenges, number of submissions within the deadline, evolution of submission of MCs throughout the semester. Graphs tracked student participation throughout the course. Data collection, treatment, and interpretation were carried out by two researchers, with validation and reliability via review with the support of two other researchers. Qualitative data was from thematic analysis [40] of metacognitive challenge 20 (in the 6th fortnightly reflection, MC20FR6), with the following questions: 1) "What is your opinion regarding Catmming's (metacognitive) challenges? What is the level of contribution of fortnightly reflections to organize your work? Why? "; 2) "What suggestions/recommendations 


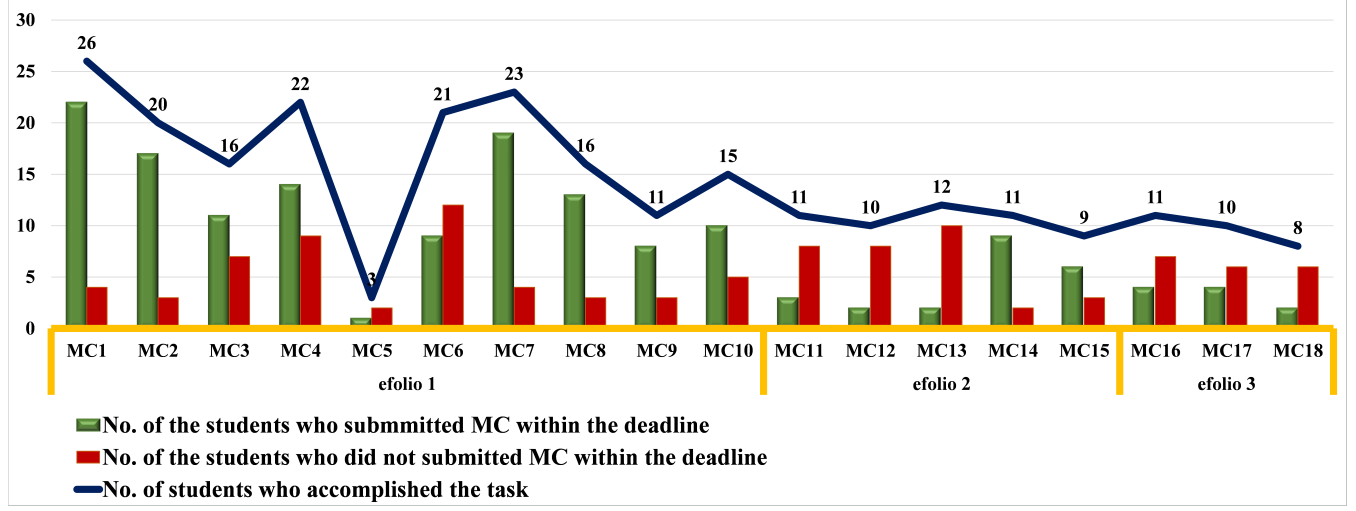

Figure 1. Evolution of submissions of MC and compliance with deadlines

to SimProgramming?" Content analysis matrices were based on students' perceptions about metacognitive challenges, and organized into subcategories, indicators, and recording units (snippets of sentences) from the analysis by two researchers. A cyclical process of improvement, synthesis, and reflection was then conducted with the two other researchers.

Students' perceptions about MC are organized under 5 subcategories': 1) difficulties completing the challenges; 2) the metacognitive challenges innovation; 3) the approach is motivating; 4) helping develop self-regulation learning strategies; 5) improvement suggestions.

\section{RESULTS AND DISCUSSION}

\section{A. Submission, deadlines and regularity}

1) Overall results: Fig. 1 shows the evolution of the number of students submitting MCs, within and outside deadlines. There is higher submission in the e-folio 1 period. Along efolios, the trend was of decreasing submissions.

MC5 saw a marked decrease in the number of students submitting MCs. This MC asked students to explain the team's roles. One reason for the decrease may be difficulties establishing group work. Teams were optional, and all students opted for the individual work modality.
In MC6 and MC7 the number of students submitting metacognitive challenges returned to the previous levels. However, after MC7 (still in e-folio 1), the number of students submitting metacognitive challenges decreased in each submission, especially when considering within deadlines.

One of the obstacles identified in previous work [8], [37] (drop in submissions between the periods of e-folios) remained. Although there is a regular effect between e-folio 2 and e-folio 3, there is some improvement in relation to the first iteration [37]. Fig. 2 shows the number of metacognitive challenges submitted by each student. S1 $(n=17), S 35$, and S52 $(n=16)$ were the students accomplishing the most MCs. Students S39, S63, and S64 did not deliver any MCs $(n=0)$. Half of the students (S6, S8, S21, S34, S35, S36, S38, S42, S44, S45, S46, S52, S53, S56, S59) submitted 50\% or more of the requested MCs $\left(\mathrm{n}_{i}, 9\right)$. The other $50 \%$ of students (S16, S23, S25, S37, S39, S40, S41, S43, S46, S50, S54, S57, S60, S62, S63, S64) submitted less than half $\left(n_{i} 8\right)$ of the MCs.

Compared to the first iteration [37], there was an increase in the number of students submitting MCs and in the quantity of MCs submitted throughout the course. The adaptation made to the instructional design from RF to MC was deemed successful

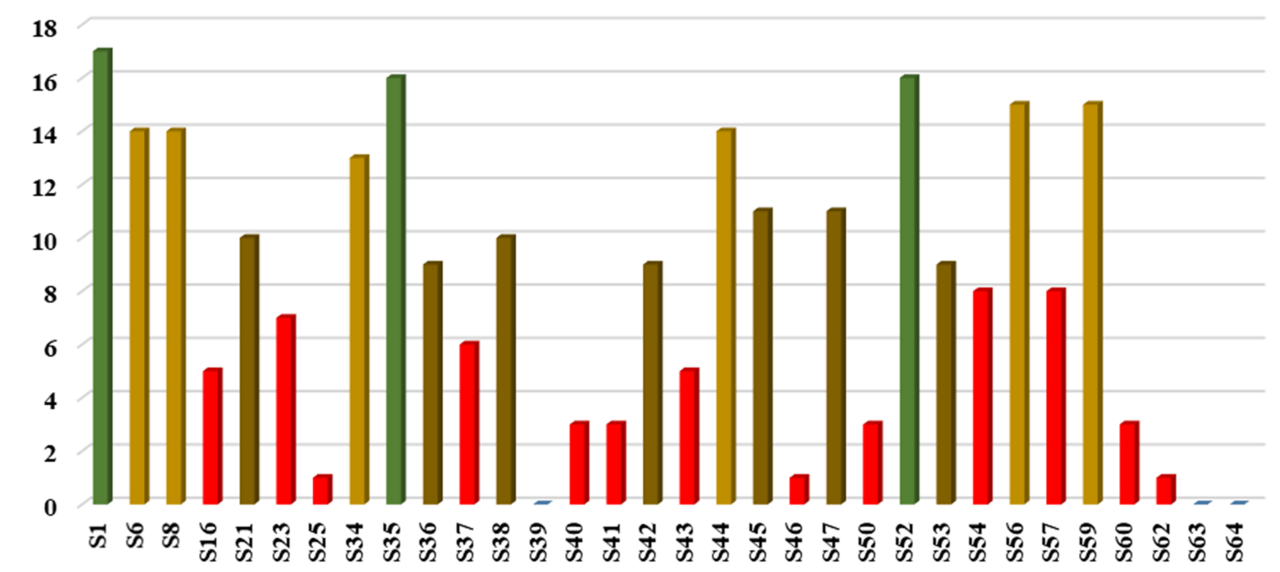

Figure 2. Number of MC submitted by each student 
due to the greater involvement of students in this type of activities, as recommended by the literature [18], [28].

2) Specific results about MC Type 1: Metacognitive challenges as fortnightly reflections about the learning progress: In fig. 3, we present evolution of FR submissions (MC6, MC10, MC13, MC15; MC17, MC18). None of these fortnightly reflections had the participation of all students. There was also a decrease in the number of submissions over time, although with stabilization in the number of students in the last three reflections. The FR with highest submissions was the first - MC6 $(n=21)$. The lowest submissions were for the last - MC18 (n=8).

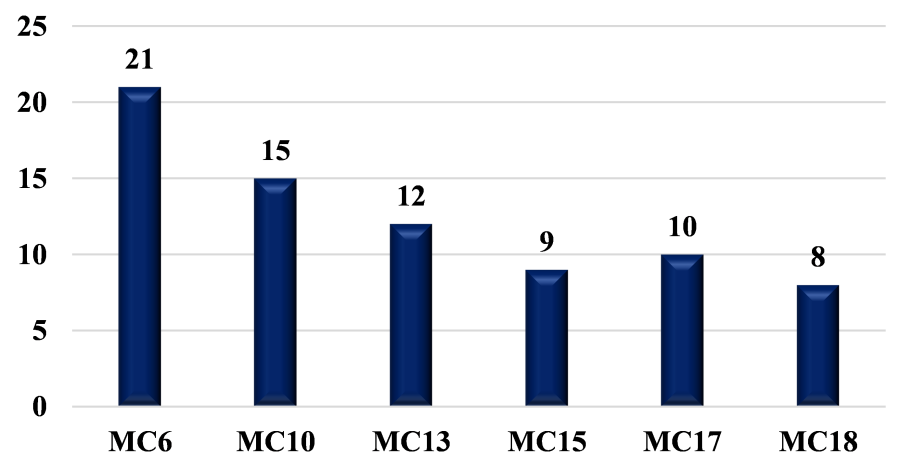

Figure 3. Number of students that submitted the fortnightly reflections (MC type 1)

Fig. 4 analyses submissions of fortnightly reflections per student: 9 of the 32 students never submitted a FR (S39, S40, S46, S50, S25, S60, S62, S63, S64). Of those who did, only 3 students (S1, S52 and S59) delivered all the FR. As for the remaining students, 5 delivered 5 FR (S8, S34, S35, S53 and S59). 1 student delivered 4 FR (S44) and 2 students delivered 3 FR (S45 and S54). 7 students delivered 2 FR (S21, S23, S36, S37, S38, S47, S57). 4 students delivered 1 FR (S16, S41, S42, S43).

Fig. 5 shows the number of students who submitted their fortnightly reflections within each e-folio period and whether within deadlines. The maximum number of submitted FRs was in MC6. The minimum was in the final one, MC18. The number of students submitting fortnightly reflections was decreasing after each e-folio, within and outside deadlines (MC13 and MC17). Particularly, after delivery of e-folio 1, there was an abrupt decrease in the number of students who delivered their reflections within the deadline (MC13).

3) Specific results about MC Type 2: Metacognitive challenges to promote self-reflection about programming concepts: In fig. 6, we see the same tendency of decreasing submissions over time as with MC type 1, with a plateau in the number of submissions in the last $6 \mathrm{MCs}$ (MC9, MC11, MC12, MC14, MC16).

Fig. 7 shows that 6 of the 32 students (S1, S35, S44, S52, S56, S59) delivered almost all the type 2 MCs ( $\left.\mathrm{n}_{i} 9\right) .3$ students (S39, S63, S64) did not submit any MC. These students also did not deliver any of the FR (MC type 1). Likewise, it appears that $50 \%(n=16)$ of the students (S1, S6, S8, S21, S34, S35, S36, S38, S42, S44, S45, S47, S52, S56, S57, S59) submitted equal or more than half of the MC type 2. And another $50 \%$ $(\mathrm{n}=16)$ of students (S16, S23, S25, S37, S39, S40, S41, S43, S46, S50, S53, S54, S60, S62, S63, S64) submitted less than $50 \%$ of MC type 2.

There is greater tendency for students to submit MCs of type 2 than those of type 1 constrating figs. 7 and 4 . This may indicate more interest and focus of students on programming content (type 2) than on reflecting upon their learning process (type 1). The evidence shows that the MC approach has promising results to encourage students to reflect on their learning, suppressing the need reported in [23], in particular with type $2 \mathrm{MCs}$, associated with domain knowledge [26] (in this case, programming).

Fig. 8 shows the number of students who submitted their type $2 \mathrm{MCs}$, between each e-folio period, within and outside deadlines. the maximum occurred in $\mathrm{MC} 1$ and the minimum in MC12, both within and outside deadlines. The number of students who submitted MC type 2 fluctuated between e-folio 1 and e-folio 2, but stabilized between e-folio 2 and e-folio 3. Contrary to what occurred with FRs (MC type 1 - see fig. $5)$, there is a higher rate of students complying with deadlines in e-folio 1. Only during e-folio 2 (MC11 and 12) and in the last MC did most students submit after the deadline.

4) Relationship between MC submission and average mark in the e-folios: Fig. 9 shows that students who submitted a

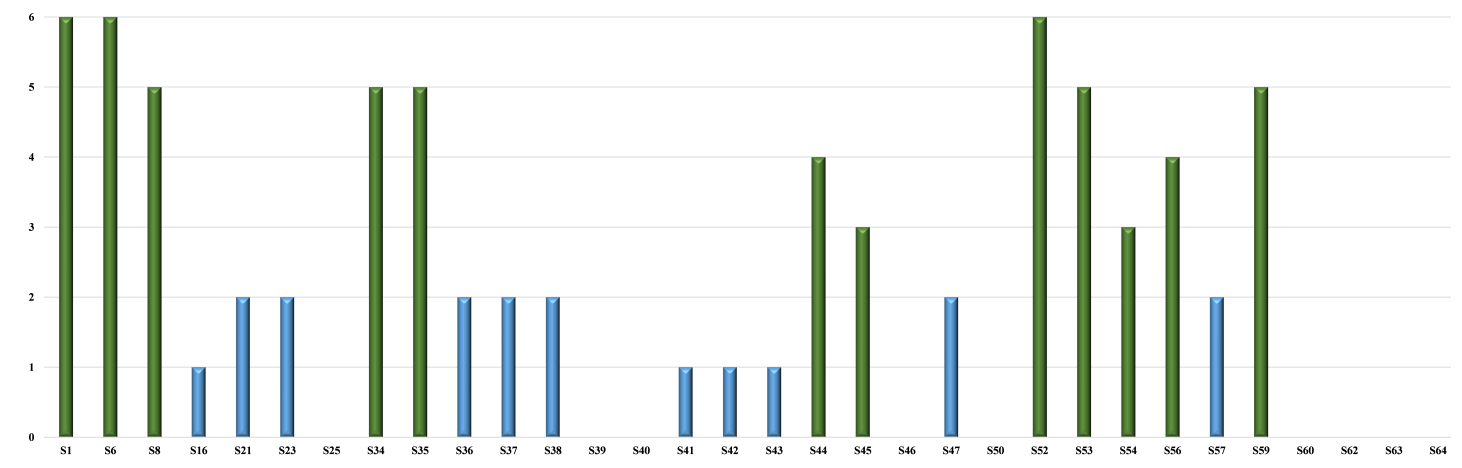

Figure 4. Number of FR (MC type 1) submitted by each student 


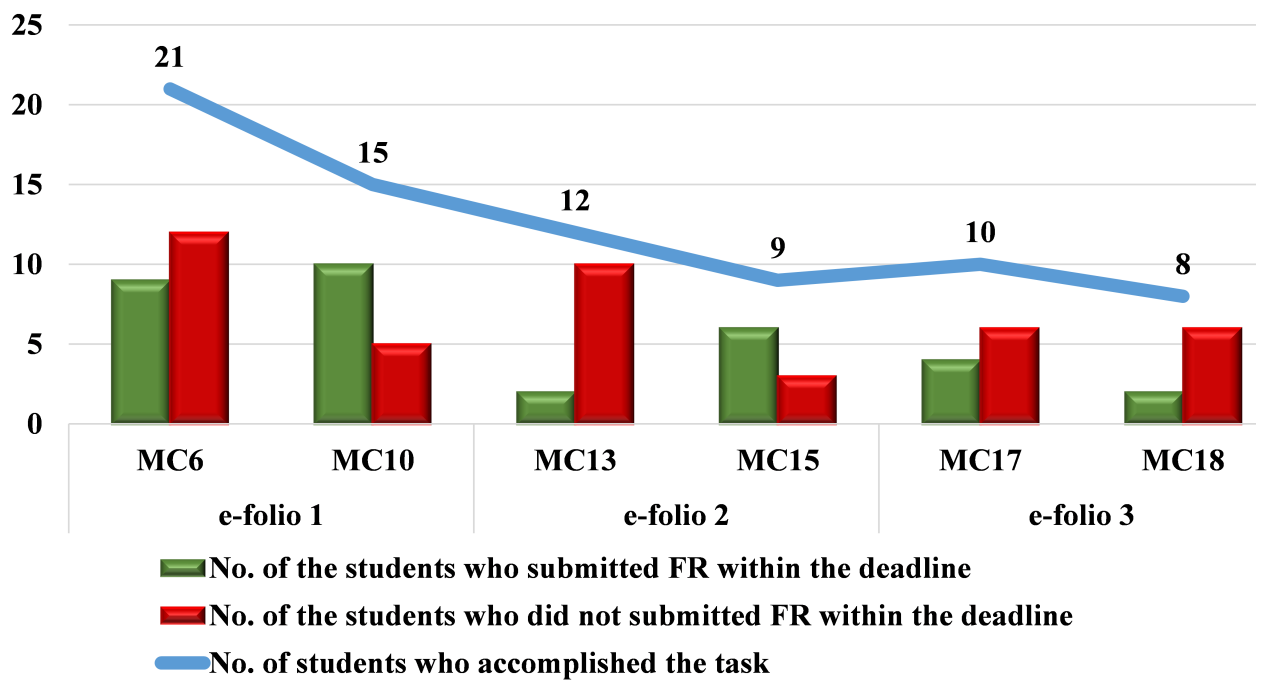

Figure 5. Number of FR submitted by students and relationship with e-folios

greater number of MCs (e.g. $\mathrm{n}_{i}$ 13) also had a positive grade in the set of e-folios ( 1 1, S34, S35, S42, S44, S52, S56, S59, S6, S8), confirming a positive relationship between academic success and the adoption of approaches that stimulate metacognition and SRL [18], [27], [28].

Likewise, low MC submission (less than half, $n_{i} 9$ ) is associated with low results obtained in the e-folios. I.e., a relationship between low MC submission and negative learning outcomes (see S16, S23, S25, S37, S39, S40, S41, S43, S46, S50, S54, S57, S60, S62, S63, S64), confirming that low metacognitive awareness is a predictor of insufficient performance [15].

However, there students who submitted about 50\% MC $\left(\mathrm{n}_{\dot{6}} 8\right)$ but were unable to obtain a positive average mark in the e-folios. These students (S21, S38, S42, S45, S47, S53) obtained only a mark in the first e-folios that proved insufficient.

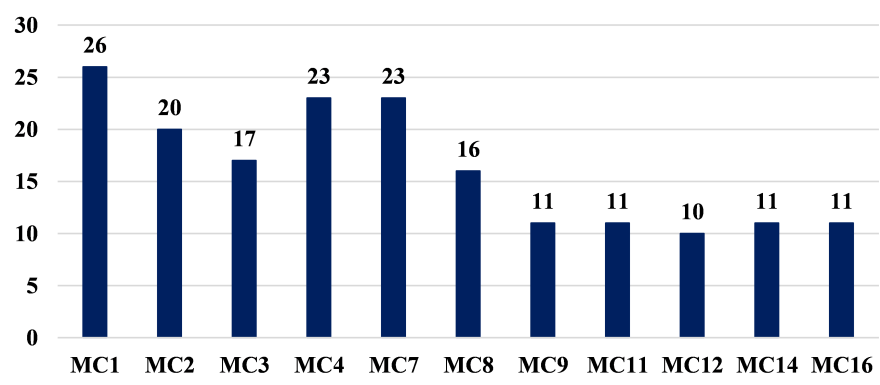

Figure 6. Number of students that submitted the MC type 2.

\section{B. Student's perceptions about metacognitive challenges}

Students expressed the following perceptions about metacognitive challenges: difficulties completing the challenges (subcategory 1); the metacognitive challenges are innovative (subcategory 2); the approach is motivating (subcategory 3); helped them develop self-regulation learning strategies (subcategory 4); and improvement suggestions (subcategory 5).

Difficulties completing the challenges: three students expressed their difficulties to complete the challenges: lack of time because of professional demands $(n=1)$; time management difficulties associated with the COVID19 pandemic $(\mathrm{n}=1)$; and unspecified time management difficulties $(\mathrm{n}=1)$, one example: "Professional work often interrupts what is necessary to be able to complete the challenges posed." $\mathrm{S} 8$, $5 / 30 / 2020$

Subcategory 2: One student mentioned metacognitive challenges as innovative and allowing one to go beyond readings: "The organization in sprints is a new and innovative way of approaching (...) seems very appropriate and motivating to me, since it doesn't just send us to pages in a book." S1, 6/1/2020

Subcategory 3: Metacognitive challenges are considered a motivating approach because they help them monitor accomplishment of tasks $(\mathrm{n}=3)$, for example: "It keeps pace with our own development." S1, 6/1/2020

One student stated: "(...) Catmming's challenges (...) were always presented in such a way that it felt a 'natural' evolution of the themes." S54, 06/07/2020

They considered metacognitive challenges are interesting $(\mathrm{n}=2)$, e.g: "Catmming's challenges are interesting (...)" S54, 06/07/2020

And, also that it is an appropriate approach: "It seems very appropriate and motivating (...)" S1, 01/06/2020

Subcategory 4: the metacognitive challenges help in the development of self-regulation learning strategies, namely in the self-reflection about students' work $(\mathrm{n}=1)$ and in organization $(\mathrm{n}=2)$, e.g.:"The biweekly reflections help me to understand how I managed to deal with the proposed challenges (...)" S54, 07/06/2020

Subcategory 5: One student considered that an aspect to be improved would be the integration of other multimedia 


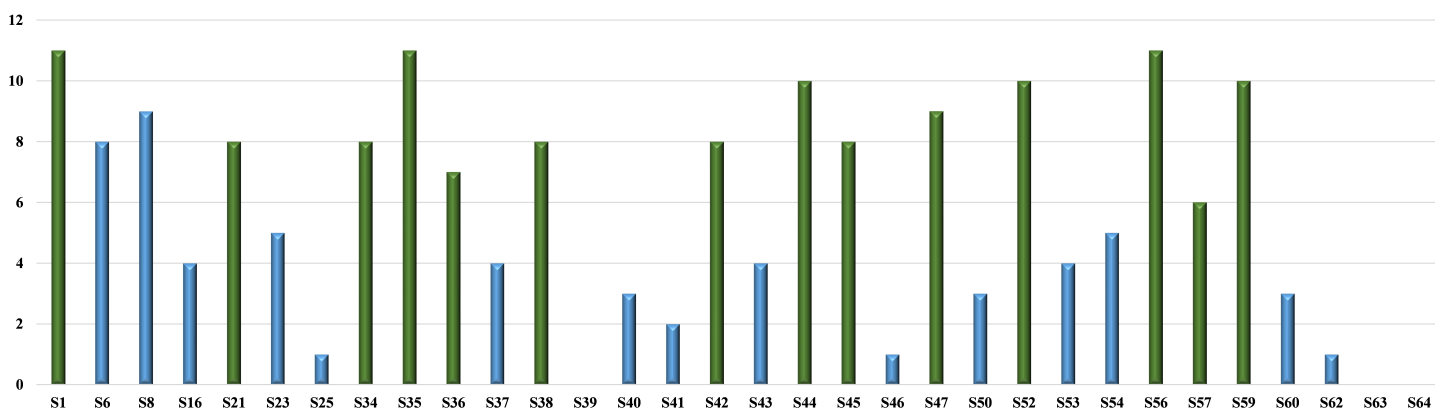

Figure 7. Number of MC type 2 submitted by each student

elements $(\mathrm{n}=1)$ : "(...) I missed some support from videos to help me." S52, 06/03/2020

According to the students' perceptions, MCs were an innovative and motivational approach that contributed to helping students better understand the evolution of their work and to develop some self-regulation learning strategies: organization of their study, and their awareness and reflection abilities. However, some students reported difficulties carrying out the MCs, mostly related to time management or professional and personal reasons, and in some cases due to the COVID19 pandemic. As an improvement to the MC, one student mentioned the inclusion of multimedia elements.

\section{LIMITATIONS}

This research focused on a descriptive and interpretative analysis of data. Although the reliability has been guaranteed through internal vetting of the project researchers, it is necessary in future work to triangulate the data obtained from other sources and carry out in-depth statistical analysis. Likewise, it is necessary to conduct a content analysis of the MCs and relate it to other data.

\section{CONCLUSIONS AND FINAL THOUGHTS}

In the second iteration of e-SimProgramming, there is a tendency towards decreasing the submission of MCs of both types 1 and 2, mainly between e-folios 1 and 2, as observed previously in the first iteration. However, in the transition between e-folios 2 and 3 the trend in submission of MCs remained regular, which differed from the first iteration [37]. We conclude that there is promising evidence regarding the adoption of MCs as an approach to involve students in activities of a high cognitive level and consequently improve their performance in learning.

There is a lot of fluctuation in meeting the deadlines for submission of MCs of types 1 and 2, in particular in e-folio 2 and e-folio 3. However, in e-folio 1, students submitted MCs type 2 within the established deadlines, revealing that when reflections are more directly related to the course content (in this case programming) students show greater interest in meeting deadlines. This is reinforced by the overall greater submission of MCs of type 2 than of type 1, indicating greater interest of students in reflecting on specific learning content than in reflecting on the learning process.

Students who regularly submitted the MCs had better average grades, and low submission of MCs by students led to poorer performance and failure. However, in future work it is important to find out what happened in specific situations of students who, despite having submitted a considerable number of MCs, were not able to succeed in the course.

Overall, students' perceptions of MCs are positive, as they consider them to be innovative, motivational, helpful to develop self-regulatory learning strategies, and providing for greater self-awareness and self-knowledge about their skills.

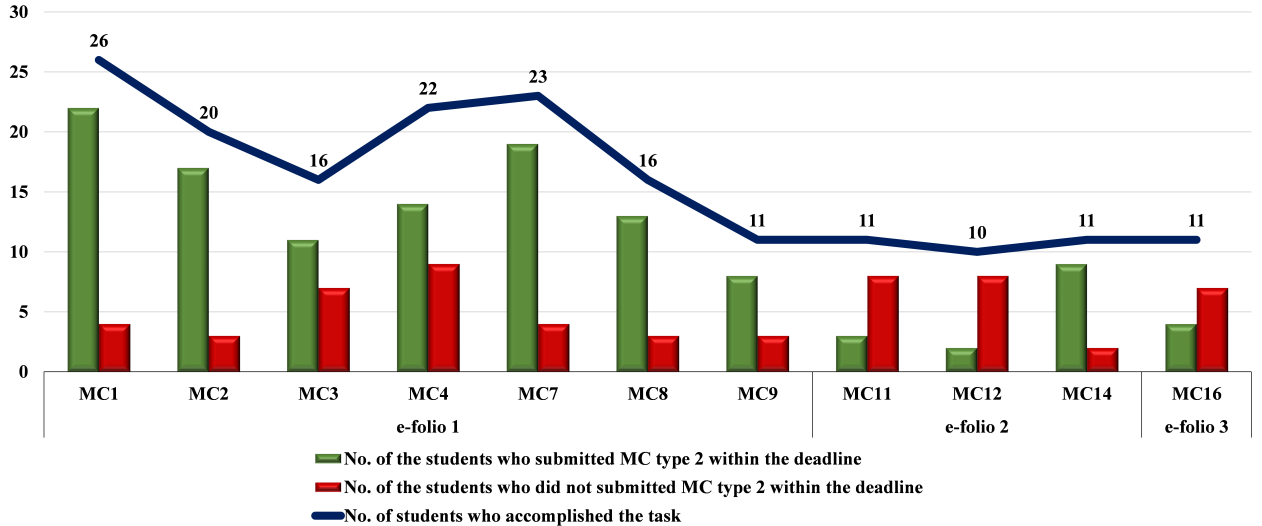

Figure 8. Number of MC type 2 submitted by students and relationship with e-folios. 


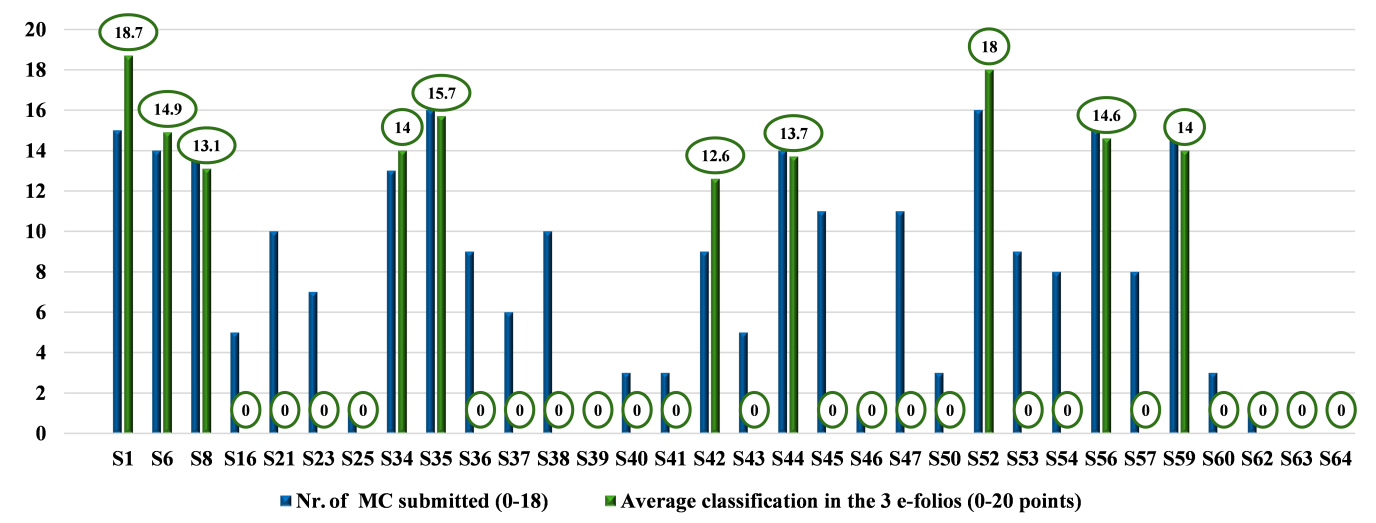

Figure 9. Relationship between MC submission and average mark in the e-folios

However, in future work it is necessary to understand how students can be helped to overcome reported difficulties, such as time management.

As improvements in the instructional design of the MCs, we will consider the adoption of tools that help students to be more aware of the state of progress of their learning through: visualizations about the tasks that have been submitted and those that remain to be submitted, and alerts about submission deadlines. In addition, it is essential that there is feedback from the teacher regarding MC. It is necessary to proceed with the adoption of pedagogical strategies that help students to better define a learning plan that allows them to organize, manage their time, and overcome the reported difficulties.

With future work, the content of the MC will be analyzed to identify what type of SCRL strategies were mentioned by the students and those that are less evident, to understand if the students' self-perceptions (self-awareness, self-knowledge, self-assessment) are balanced with the results obtained (selfperception-result obtained).

The adoption of MC is an approach with potential, helping students self-reflect upon their learning process and that can be implemented in other fields of knowledge involving the transition from initial skills to proficiency.

\section{REFERENCES}

[1] D. Pedrosa, J. Cravino, L. Morgado, C. Barreira, R. R. Nunes, P. Martins, and H. Paredes, "SimProgramming : The development of an integrated teaching approach for computer programming in higher education," in INTED2016 Proceedings - 10th International Technology, Education and Development Conference March 7th-9th, 2016 - Valencia, Spain, L. Gómez Chova, A. López Martínez, and I. Candel Torres, Eds., Valencia, Spain: IATED Academy, Mar. 2016, pp. 7162-7172. DOI: 10.21125/inted.2016.0699.

[2] D. Pedrosa, J. Cravino, L. Morgado, and C. Barreira, "Self-regulated Learning in Computer Programming: Strategies Students Adopted During an Assignment," in Immersive Learning Research Network, C. Allison, L. Morgado, J. Pirker, D. Beck, J. Richter, and C. Gütl, Eds. vol. 621, Cham: Springer International Publishing, 2016, pp. 87-101. DOI: $10.1007 / 978-3-319-41769-17$.

[3] D. Pedrosa, J. Cravino, L. Morgado, and C. Barreira, "Self-regulated learning in higher education: Strategies adopted by computer programming students when supported by the SimProgramming approach,' Production, vol. 27, no. spe, 2017. DOI: 10.1590/01036513.225516
[4] D. Pedrosa, J. Cravino, L. Morgado, and C. Barreira, "Co-regulated Learning in Computer Programming: Students Co-reflection About Learning Strategies Adopted During an Assignment," en, in Technology and Innovation in Learning, Teaching and Education, M. Tsitouridou, J. A. Diniz, and T. A. Mikropoulos, Eds., vol. 993, Cham: Springer International Publishing, 2019, pp. 13-28. DOI: 10.1007/ 978-3-030-20954-4_2.

[5] R. R. Nunes, D. Pedrosa, L. Morgado, P. Martins, H. Paredes, J. Cravino, and C. Barreira, "SimProgramming: Uma abordagem motivacional para a aprendizagem de alunos intermediários de programação," Recife, Pernambuco, Brasil, Oct. 2017, p. 1099. DOI: 10.5753/cbie.wcbie.2017.1099.

[6] R. R. Nunes, G. Cruz, D. Pedrosa, A. M. Maia, L. Morgado, H Paredes, J. Cravino, and P. Martins, "Motivating Students to Learn Computer Programming in Higher Education: The SimProgramming Approach,” en, in Technology and Innovation in Learning, Teaching and Education, A. Reis, J. Barroso, J. B. Lopes, T. Mikropoulos, and C.-W. Fan, Eds., vol. 1384, Series Title: Communications in Computer and Information Science, Cham: Springer International Publishing, 2021, pp. 506-518. DOI: 10.1007/978-3-030-73988-1_41.

[7] D. Pedrosa, L. Morgado, and J. Cravino, "Abordagem eSimProgramming: Primeiras alterações para implementação em contexto on-line e reflexões," in CNAPPES. 19-6. " Congresso Nacional de Práticas Pedagógicas no Ensino Superior, Instituto Politécnico de Santarém, 2019, p. 50.

[8] D. Pedrosa, L. Morgado, J. Cravino, M. M. Fontes, M. Castelhano, C. Machado, and E. Curado, "Challenges Implementing the SimProgramming Approach in Online Software Engineering Education for Promoting Self and Co-regulation of Learning," in 2020 6th International Conference of the Immersive Learning Research Network (iLRN), San Luis Obispo, CA, USA: IEEE, Jun. 2020, pp. 236-242. DOI: $10.23919 /$ iLRN47897.2020.9155183.

[9] J. T. G. on Computer Engineering Curricula, "Computer Engineering - Curricula 2016 - Curriculum Guidelines for Undergraduate Degree Programs in Computer Engineering," Association for Computing Machinery (ACM) \& IEEE Computer Society, USA, Tech. Rep., Dec. 2016, ISBN: 978-1-4503-4875-1.

[10] R. Garcia, K. Falkner, and R. Vivian, "Systematic literature review: Self-Regulated Learning strategies using e-learning tools for Computer Science," en, Computers \& Education, vol. 123, pp. 150-163, Aug. 2018. DOI: 10.1016/j.compedu.2018.05.006.

[11] A. Burgess, A. M. Kelly, E. M. Butterfield, J. Keppler, D. McClenahan, K. Guillemette, and M. Phon, Software Engineering Competency Model, en. USA: IEEE Computer Society, 2014.

[12] B. J. Zimmerman, "Becoming a Self-Regulated Learner: An Overview," Theory Into Practice, vol. 41, no. 2, pp. 64-70, May 2002. DOI: 10.1207/s15430421tip4102_2.

[13] R. S. Jansen, A. v. Leeuwen, J. Janssen, R. Conijn, and L. Kester, "Supporting learners' self-regulated learning in Massive Open Online Courses," Computers \& Education, vol. 146, p. 103771 , 2020. DOI: 10.1016/j.compedu.2019.103771.

[14] B. J. Zimmerman, "From Cognitive Modeling to Self-Regulation: A Social Cognitive Career Path," Educational Psychologist, vol. 48, 
no. 3, pp. 135-147, Jul. 2013, Publisher: Routledge. DOI: 10.1080/ 00461520.2013 .794676

[15] S. K. Davis and A. F. Hadwin, "Exploring differences in psychological well-being and self-regulated learning in university student success," en, Frontline Learning Research, vol. 9, no. 1, pp. 30-43, Jan. 2021. DOI: $10.14786 /$ flr.v9i1.581.

[16] J. Flavell, "Metacognition and Cognitive Monitoring: A New Area of Cognitive-Developmental Inquiry.," 1979. DOI: 10.1037/0003066X.34.10.906.

[17] L. D. Frazier, B. L. Schwartz, and J. Metcalfe, "The MAPS model of self-regulation: Integrating metacognition, agency, and possible selves," en, Metacognition and Learning, Jan. 2021. DOI: 10.1007/ s11409-020-09255-3.

[18] L. Anthonysamy, A.-C. Koo, and S.-H. Hew, "Self-regulated learning strategies and non-academic outcomes in higher education blended learning environments: A one decade review," en, Education and Information Technologies, vol. 25, no. 5, pp. 3677-3704, Sep. 2020. DOI: $10.1007 / \mathrm{s} 10639-020-10134-2$.

[19] T. Lehmann, I. Hähnlein, and D. Ifenthaler, "Cognitive, metacognitive and motivational perspectives on preflection in self-regulated online learning," en, Computers in Human Behavior, vol. 32, pp. 313-323, Mar. 2014. DOI: 10.1016/j.chb.2013.07.051.

[20] J. Prather, B. A. Becker, M. Craig, P. Denny, D. Loksa, and L. Margulieux, "What Do We Think We Think We Are Doing? Metacognition and Self-Regulation in Programming," in Proceedings of the 2020 ACM Conference on International Computing Education Research, ser. ICER '20, Virtual Event, New Zealand: Association for Computing Machinery, Aug. 2020, pp. 2-13. DOI: 10.1145/3372782. 3406263.

[21] M. Dindar, S. Järvelä, and H. Järvenoja, "Interplay of metacognitive experiences and performance in collaborative problem solving," en, Computers \& Education, vol. 154, p. 103922 , Sep. 2020. DOI: 10. 1016/j.compedu.2020.103922.

[22] C. Schuster, F. Stebner, D. Leutner, and J. Wirth, "Transfer of metacognitive skills in self-regulated learning: An experimental training study," en, Metacognition and Learning, vol. 15, no. 3, pp. 455477, Dec. 2020. DOI: 10.1007/s11409-020-09237-5.

[23] Y. R. Kim, M. S. Park, T. J. Moore, and S. Varma, "Multiple levels of metacognition and their elicitation through complex problem-solving tasks," en, The Journal of Mathematical Behavior, vol. 32, no. 3, pp. 377-396, Sep. 2013. DOI: 10.1016/j.jmathb.2013.04.002.

[24] J. Y. Kim and K. Y. Lim, "Promoting learning in online, ill-structured problem solving: The effects of scaffolding type and metacognition level," en, Computers \& Education, vol. 138, pp. 116-129, Sep. 2019 DOI: 10.1016/j.compedu.2019.05.001.

[25] R. Azevedo, "Theoretical, conceptual, methodological, and instructional issues in research on metacognition and self-regulated learning: A discussion," en, Metacognition and Learning, vol. 4, no. 1, pp. 87-95, Apr. 2009. DOI: 10.1007/s11409-009-9035-7.

[26] X. Lin, "Designing metacognitive activities," en, Educational Technology Research and Development, vol. 49, no. 2, pp. 23-40, Jun. 2001. DOI: $10.1007 / \mathrm{BF} 02504926$.

[27] K. Craig, D. Hale, C. Grainger, and M. E. Stewart, "Evaluating metacognitive self-reports: Systematic reviews of the value of selfreport in metacognitive research," en, Metacognition and Learning, vol. 15, no. 2, pp. 155-213, Aug. 2020. DOI: 10.1007/s11409-02009222-y.

[28] J. Broadbent and W. L. Poon, "Self-regulated learning strategies \& academic achievement in online higher education learning environments: A systematic review," The Internet and Higher Education, vol. 27, pp. 1-13, 2015. DOI: 10.1016/j.iheduc.2015.04.007.

[29] R. Azevedo, D. C. Moos, J. A. Greene, F. I. Winters, and J. G Cromley, "Why is externally-facilitated regulated learning more effective than self-regulated learning with hypermedia?" en, Educational Technology Research and Development, vol. 56, no. 1, pp. 45-72, Feb. 2008. DOI: 10.1007/s11423-007-9067-0.

[30] T. Apps, K. Beckman, S. Bennett, B. Dalgarno, G. Kennedy, and L. Lockyer, "The role of social cues in supporting students to overcome challenges in online multi-stage assignments," en, The Internet and Higher Education, vol. 42, pp. 25-33, Jul. 2019. DOI: $10.1016 / \mathrm{j}$ iheduc.2019.03.004.

[31] K. Cagiltay, "Scaffolding strategies in electronic performance support systems: Types and challenges," Innovations in Education and
Teaching International, vol. 43, no. 1, pp. 93-103, Feb. 2006. DOI: 10.1080/14703290500467673.

[32] D. Verpoorten, W. Westera, and M. Specht, "Using reflection triggers while learning in an online course: Using reflection triggers while learning," en, British Journal of Educational Technology, vol. 43 , no. 6, pp. 1030-1040, Nov. 2012. DOI: 10.1111/j.1467-8535.2011. 01257.x.

[33] R. A. Beghetto, What If?: Building Students' Problem-Solving Skills Through Complex Challenges, en. ASCD, Aug. 2018, Google-BooksID: 7wRuDwAAQBAJ.

[34] A. Pereira, A. Q. Mendes, L. Morgado, L. Amante, and J. Bidarra, Modelo pedagógico virtual da Universidade Aberta: para uma universidade do futuro. Universidade Aberta, 2007.

[35] A. Kirkwood and L. Price, "Technology-enhanced learning and teaching in higher education: What is 'enhanced' and how do we know? A critical literature review," en, Learning, Media and Technology, vol. 39, no. 1, pp. 6-36, Jan. 2014. DOI: 10.1080/17439884.2013 770404.

[36] M. Chaves, "Abordagem SimProgramming : E-learning no ensino de programação em ambiente virtual," Master dissertation, Universidade Aberta, Lisboa, Portugal, 2017.

[37] J. P. C. C. Cravino, D. Pedrosa, L. Morgado, M. Castelhano, and E. Curado, "Uma proposta para apoiar a autorreflexão das aprendizagens em contexto on-line," por, ieTIC2020: Livro de Atas - VI Conferência Ibérica de Inovação na Educação com TIC, pp. 288-301, 2020.

[38] M. M. Fontes, D. Pedrosa, T. Araújo, C. Morais, A. Costa, J. Cravino, and L. Morgado, "Narrative immersion and students' perceptions in an online software programming course," in 2021 7th International Conference of the Immersive Learning Research Network (iLRN), 2021, submitted.

[39] L. Cohen, Research Methods in Education, en, 5th ed. Routledge, Sep. 2002. DOI: 10.4324/9780203224342.

[40] V. Braun and V. Clarke, "Using thematic analysis in psychology," en, Qualitative Research in Psychology, vol. 3, no. 2, pp. 77-101, Jan. 2006. DOI: 10.1191/1478088706qp063oa. 